\title{
THE ROLE OF REFLECTION SKILLS IN THE CONSTRUCTION OF COGNITIVE STRUCTURE
}

\author{
M. Krivoshapkova* \\ Postgraduate student (PhD), Faculty of Education, Trakia University, Stara Zagora, Bulgaria
}

\begin{abstract}
This article presents options for pedagogical interaction that include methods and techniques for formation of reflective mechanisms of developing a reflective strategy of thinking in problem solving. Reflection, in terms of an intellectual reflection (reflection on their own cognitive activity) and its reflection in prakseological aspect (reflection on application of knowledge, self-knowledge through manifestation of their skills in product activity) are used in the training strategies of primary school age. This is the age when the foundations of algorithms for learning are created and in particular - the primary skills of reflective thinking. The research follows the model of reflective learning and formation of skills for reflective thinking and demonstrates the results of a survey carried out among students at elementary school age to register the reflective skills in the development of cognitive structure.
\end{abstract}

Key words: reflective skills, reflective mechanisms, congnitive structure, pedagogical interaction

This survey presents variations of pedagogical interaction that include methods and techniques for the formation of reflexive mechanisms in the development of the cognitive structure of the student. The exhibition follows the model of reflexive training in building skills for reflective thinking and offers the results of an experimental pedagogical interaction.

Usually in terms of cognitive structure we mean a combination of knowledge, the ability to think and problem solving.

Storage of information in horizontal and vertical order and hierarchical dependence is the first stage of the cognitive structure of the child. Besides the stored facts, we understand in knowledge and mastery of skills for operating information.

The second stage of the cognitive structure includes skills for operating with information in order to build and modeling of new knowledge or the discovery of new knowledge. Often this

${ }^{*}$ Correspondence to: Mariana Krivoshapkova, postgraduate student (PhD), Faculty of Education, Trakia University, Stara Zagora, Bulgaria,

krivoshapkova@abv.bg stage is called heuristic, because it requires the availability of skills for problem solving and the development of a strategy to address it. This defines the entire spectrum of cognitive procedures - from skills to establish sincretic skills, ie look top- problem and the whole situation, to skills of selection of tools and building strategy. So this argument cognitive structure complements Dörner in the functional part by stating what is heuristic structure 'heuristic structure can be imagined as composed of quality analyzer to problems and tasks, from a battery of methods / heuristicisms / and control system established ways of solving the problem. " $(6 ; 47)$ When we speak of heuristics it means discovering something new, significant and useful. In primary school age it is difficult to talk about heuristics, but in the sense of discovery, each individual discovery of new knowledge can be called heuristic.

The term cognitive structure cannot be defined without understanding the intellectual reflection. (2;110-128) According to Kant's intellectual reflection contains "thinking about thinking" by typical analytical reasoning and "awareness of the grounds and sources" - a synthetic judgment which shows the construction of reflection. Vassilev called this type of reflection, thinking 
KRIVOSHAPKOVA M.

back, playing ways and means by which knowledge is acquired. Intellectual reflection includes constructing a plan that will solve the problem, mentally migrating forward in the process of cognitive activity ("forward-looking reflection"), taking into account the strengths and weaknesses of the activity. This is a typical feature anticipative mechanisms of consciousness, which is impossible without the participation of reflexive analysis.

The difference between reflection and action model of Ogurtsov justified the issue like that: "Reflection begins where deviation occurs in the sample, where they realize the frustration of the previous model ... Reflection leads to change (movement) of the models to change patterns of activity and thinking ... Reflection blocks the movement of thought and action as the previous models ...; paying mind to itself, it returns to itself, forcing it to reconstruct, to seek new grounds and to build new ideal objects ... $(2 ; 40)$

The formation of reflexive mechanisms occurs in regulation and interraction consistency between the strategies of educational impact. The utilization of information components knowledge, a compilation of the elements of relations between them, creating a level of conceptual structure, supported by the reflexive connections between elements of knowledge and relationships. This is done effectively enough as a process and sufficiently durable as knowledge through the use of methods of interaction in the learning process. In turn they function as better methods of pedagogical impact only if they are in inversely proportional relationship with the free forms of organization. This suggests the teacher alone to build stages and the training content according to school goals, the degree of reflexivity and rate of success. This achieves a flexible reflective construct a knowledgeoriented individual characteristics of each student. Coupled with the introduction of reflection as technology training, this construct builds individual cognitive structure, which already has the ability to self-organize to next cognitive level as it contains mechanisms for configuration items - reflexive skills, constructive mechanisms for cognitive correction, goal setting skills and control.

Experimental Pedagogic interaction for recording of reflexive mechanisms in forming the cognitive structure of the students was held with children of primary school age (4th grade) in "St. Kliment Ohridski" Primary School and Children's School "Eureka" (extracurricular activity for children in Municipality of Chirpan) During the experiment have been studied 8 children in both groups. Children are students with excellent grades and a keen interest in activities in science and mathematics.

For the students of the school organization the learning process has been structured according to the set educational goal, which is most common in school and in general is not only dependent as a kind of learning as follows:

Associative learning where the structure of the training is given by: preparation for the absorption of new material; presentation of new facts and evidence; comparing and abstracting of properties and relations; generalization; application of knowledge;

Operational learning, which is an expression of active approach and is characterized by a general construct of mental actions and indicators of activity. The learning process starts by introducing concepts in the process of operation and their practical application; mental activity is divided into mental actions for formation of algorithm for solving different types of problems; to internalize the objects and the verbal actions in order to pass them into mental. $(1 ; 70-74)$

For children from extracurricular school "Eureka", the process of cognitive activity was organized according to constructive theories and most used types of learning:

Top-down processing, which requires educational activities beginning with placing a complex problem, and then in the process of resolving it students have to discover and acquire the necessary knowledge and skills. This type of learning involves skills of analysis and has application in project work. One of the main features in solving the problem is the analysis of existing knowledge and competences. In this type of learning reflection is expressed through analyzing existing cognitive construct and its elements in associative signs regarding the content and in context. (5)

Discovery learning is based on self-learning by involving students in experiments. Learning by discovery motivates academic activities, enriches the accumulation of knowledge with direct experience through personal experience in the learning process. In many cases it is a prototype of heuristic mechanisms for problem solving. Learning through discovery plays a major role for approbation of different hypotheses, suggesting the inclusion of the activities of 
students of various research methods. Reflection here is expressed in skills of hypothesis detection and research methods, i.e. to create your own tools for approbation of the idea.

For the formation of skills for intellectual reflection are used the following methods: Method of heuristic observation, method of hypothesis, method of errors (method which undoubtedly requires reflection on the formation of cognitive construct), brainstorming method, heuristic research method of inversion (the summary), a method of self-organization of training and others. $(4 ; 206)$ We can add a few more efficiently organized reflexive skills methods: Method of techniques for questioning, modeling as a method of hypothesis on the result, dialog reflection as a method of forming heuristics.

For monitoring tools to register skills of reflection in educational activities of children were used problematic situations in the field of mathematics and the school subject Human and Nature.
The control apparatus of mathematics contained three tasks, two of which required finding the unknown in extended equations and finding the area of a right triangle - learning material that is not in the curriculum of mathematics at primary school and is assumed through reflection to achieve -heuristic detection of new knowledge. The use of a reflection on the relationship between geometric shapes of the task 2 and task 3 was anticipated.

When solving problems, the researcher requires verbalization of mental action by the student and justification of decisions to verify the reflexive mechanism of thought process to solve the task. In addition, apart from the worksheets with the terms of the tasks, the children are provided with colored paper drawn rectangles with the exact size of the triangles of task 2 and scissors. They were told that they are not limited by time and can use any materials and ways to work with them to solve tasks.

\section{Appendix 1}

Task 1. Find the unknown number in the equation:

4.h $+20=120$

Task 2.

The length of a rectangle is twice greater than its width. Its circumference is $24 \mathrm{~cm}$. Find the area of the rectangle.

$$
\mathrm{b}=2 \cdot \mathrm{a}
$$

a

Task 3.

Find the area of a right triangle that has a cathetus equal in length to the lengths of the sides of the rectangle of task 2 .

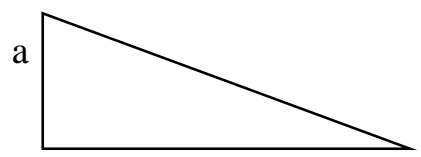

b 
Appendix 2

Standard solutions of the tasks of the experimental group and control group students:

\begin{tabular}{|c|c|c|c|}
\hline \multicolumn{2}{|c|}{$\begin{array}{l}\text { Experimental group } \\
\text { (Kids school "Eureka") }\end{array}$} & \multicolumn{2}{|c|}{$\begin{array}{l}\text { Control group } \\
\text { (Elementary School “ Sv. Kliment Ochridski”) }\end{array}$} \\
\hline Tasks Decisions & $\begin{array}{l}\text { Students comments } \\
\text { (verbal reflection) }\end{array}$ & Tasks Decisions & $\begin{array}{l}\text { Students comments } \\
\text { (verbal reflection) }\end{array}$ \\
\hline $\begin{array}{l}\text { Task 1 } \\
4 . x+20=120 \\
4 . x+20=120 \\
4 . x=120-20 \\
4 . x=100 \\
x=100: 4 \\
x=25\end{array}$ & $\begin{array}{l}\text { They are tucked into each } \\
\text { other, the two equations } \\
\text { and hide. And they feel } \\
\text { ill." } \\
\text { (The child cut out of } \\
\text { colored paper and hides } \\
\text { underneath the phrase } 4 . h \\
\text { to present it as an "empty } \\
\text { box" in the equation for } \\
\text { finding the unknown } \\
\text { number) } \\
\text { I am using } \\
\text { multiplication of sum } \\
\text { with number. So does not } \\
\text { we represent the number } \\
\text { as addition or } \\
\text { multiplication of other } \\
\text { numbers which compose } \\
\text { it. And in the brackets } \\
\text { remains whole x. } \\
\text { Unknown multiplier. } \\
\text { Then it's easy. }\end{array}$ & $\begin{array}{l}\text { Task 1 } \\
4 . x+20=120 \\
4 . x=120-20 \\
4 . x=100 \\
x=100: 4 \\
x=25\end{array}$ & $\begin{array}{l}\text { It's easy, my mom told } \\
\text { me to transfer by } \\
\text { subtracting numbers like } \\
20 \text { and so becomes a } \\
\text { "simple equation". } \mathrm{X} \text { is } \\
\text { the unknown multiplier. }\end{array}$ \\
\hline $\begin{array}{l}\text { Task } 2 \\
2 . a+2.2 . a=24 \\
a .(2+2.2)=24 \\
a .6=24 \\
a=24: 6 \\
a=4 \mathrm{~cm} \text { is the width } \\
4.2=8 \mathrm{~cm} \text { is the length } \\
4.8=32 \mathrm{~cm}^{2} \text { is the area }\end{array}$ & $\begin{array}{l}\text { I am replacing the } \\
\text { length to the width by } \\
\text { two. From the perimeter I } \\
\text { will find the width and } \\
\text { then you have both sides } \\
\text { of the area. } \\
\text { And how did you } \\
\text { know to move out "a" in } \\
\text { front of brackets? } \\
\text { It is the same as the } \\
\text { distribution property of } \\
\text { multiplication, but } \\
\text { backwards. }\end{array}$ & $\begin{array}{l}\text { Task } 2 \\
24: 6=4 \mathrm{~cm} \\
4.2=\mathrm{cm} \text { is the length } \\
4.8=32 \mathrm{~cm}^{2} \text { is the area } \\
\text { of the rectangle } \\
\mathrm{a}+\mathrm{a}+\mathrm{a}+\mathrm{a}+\mathrm{a}+\mathrm{a}=24 \\
6 . \mathrm{a}=24 \\
\mathrm{a}=4 \\
4.8=32 \mathrm{~cm}^{2} \text { is the area }\end{array}$ & $\begin{array}{l}\text { Why you divide the } \\
\text { circumference of } 6 \text { ? } \\
\text { Because the sides } \\
\text { have two lengths and two } \\
\text { widths - } 4 \text { lengths are } \\
\text { twice larger than the } \\
\text { width - } 6 \text {. } \\
\text { From the perimeter I } \\
\text { will find the sides of the } \\
\text { rectangle and it can be } \\
\text { found by adding up the } \\
\text { lengths of all sides. Right } \\
\text { length is collected twice } \\
\text { the width, to give } 6 \text { times } \\
\text { gathered width. }\end{array}$ \\
\hline $\begin{array}{l}\text { Task } 3 \\
\text { It is solvved by only } \\
\text { one student after a long } \\
\text { cutting of rectangles of } \\
\text { colored paper, folding, } \\
\text { measuring, plotting. } \\
\text { Other students also had } \\
\text { been trying different } \\
\text { options. After the } \\
\text { announcement of the } \\
\text { solution they eased } \\
\text { research work of the } \\
\text { children in the group } \\
32: 2=16 \mathrm{~cm} \text { is the } \\
\text { area of a rectangular } \\
\text { triangle. }\end{array}$ & $\begin{array}{l}\text { I found it out! } \\
\text { The rectangular } \\
\text { triangle is half of the } \\
\text { rectangle. } \\
\text { As multiplying the } \\
\text { sides, I find the face of } \\
\text { the rectangle and then } \\
\text { divide it in two. So every } \\
\text { rectangular triangle is } \\
\text { half of a rectangle. }\end{array}$ & $\begin{array}{l}\text { Task } 3 \\
\text { Task } 3 \text { is not } \\
\text { determined by the } \\
\text { students. Children do not } \\
\text { reach a solution they do } \\
\text { not know what is an area } \\
\text { of a rectangular triangle. } \\
\text { They do not use } \\
\text { colored paper to simulate } \\
\text { scenarios and variants of } \\
\text { solution. }\end{array}$ & \\
\hline
\end{tabular}


At first glance, mathematical transformations are not difficult, but a third-grader or a fourth, who does not often encounter abstract lettering values nor simplified expressions those are complex tasks that require activation of reflection on all acquired knowledge for arithmetic operations in mathematics. In the experimental group was registered heuristic for detection of the formula for finding the area of a right triangle.

In the experiment a mistake of the investigator is that the emotional response of heuristic decision was not anticipated. After the announcement of the solution the other students stopped their attempts to solve the problem, since they had already found a solution.

Algorithmic and heuristic thinking occurs in the ratio of the foundation and superstructure. It is not possible to achieve good heuristic thinking without algorithmic operation that contained in "steps" its main qualitative information that defines the parameters of the phenomenon or problem task. Good knowledge of the structure, the algorithm, enables deployment of thinking in the direction of operations and possible solutions to the problem.
It is necessary to learn concepts through special exercises and research tasks to provoke a different type of mental operations with them. All this requires a different type of organization of work where the child is free from the obligation to answer, to be provoked to create hypotheses and to investigate them, to be able to work with their mistakes, to be able to verify the accuracy of the accumulated empirical material and their solutions.

The control apparatus of the Subject - Human and Nature contains 10 questions with open answers. We have used the rubric "The wise man asks" of the draft textbook in Human and Nature $3^{\text {rd }}$ grade of "Tilia" editors company, authors Assoc. Prof. Vanya Petrova, Mariana Krivoshapkova, Natalia Kachamakov. (3) The criteria is registering the expressed in indicators of true and justified answer to the question: true and justified answer; true but unjustified answers; incorrect and unjustified answer. The results show the presence of reflection in terms of cognitive construct utilized and understanding of the relationships between phenomena and processes in nature.

\section{Appendix 3}

The Wise Man asks:

\section{A substance may be in the composition of different bodies. Is it true?}

Yes, because.

No, because

\section{Milk does not have a form, but has a certain mass and volume. Is it true?}

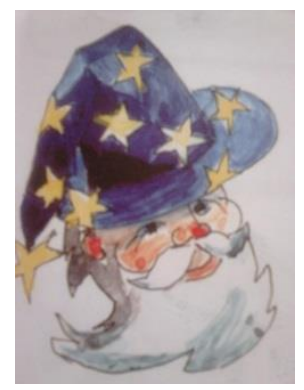

Yes, because.

No, because

\section{The air occupies any part of the space on the planet. Is it true?}

Yes, because.

No, because

\section{In nature, water is continuously passed from one physical state to another. Is it true?}

Yes, because 
No, because

5. I doubt that plants are living organisms because they are attached to the ground with the roots and do not move.

They are alive because.

They are not alive because

6. Animals do not need extra clothing during the winter months. Is it true?

Yes, because.

No, because

7. Forests are a national treasure. Is it true?

Yes, because.

No, because

\section{Aquatic animals also breathe. Is it true?}

Yes, because.

No, because

\section{Human is a mammal. Is it true?}

Yes, because.

No, because

10. Food chains depend on the conditions of life of the plants. Is it true?

Yes, because

No, because 
$75 \%$ of students in the experimental group give correct and justified answers; $12.5 \%$ answer correctly, but does not justify their answers; $12.5 \%$ respond with incorrect and unjustified answers.

$62.5 \%$ of students in the control group give correct and justified answers; 25\% answer correctly, but they do not justify their answers; $12.5 \%$ respond with incorrect and unjustified answers.

It is considered that for the indicator - correct but unjustified answer, reflection is not determined and registered. Regarding the indicator - gives incorrect answer but justifies their answer, the process of reflection is present. To sum up for the two groups, reflexive mechanisms are observed in $56 \%$ of the children studied.

Based on the basic parameters of reflexivity, we can build a model scheme for the construction of a reflexive model of training to meet the main goal - the establishment of adequate personal tools in the child awareness, projection and interaction with the surrounding reality:

Information elements and Elements of the relationship between components,

Methods of interaction and Free organizational structure of educational process,

Reflexive construct of knowledge and Heuristic technologies in education building cognitive construct based on the principle of selforganization.

If we consider the personal cognitive construct of the individual as a system of interacting components - their concepts and structures, their skills to work with information, skills to apply knowledge - reflexive mechanisms are the instrumental of implementing the relationship between cognitive elements and they ensure system-factor - goal setting. To ensure and achieve educational goal it requires better forecasting, selection of the pedagogical strategy - methods and techniques, developing skills for self-reflection and introspection and observation skills of the activity, i.e. formation of reflexive mechanisms for training and self-learning students.

\section{REFERENCES}

1. Andreev M., Didactics, National Education, S. 1987

2. Vasilev K. Reflection in knowledge and selfknowledge practice, ed. Marcos, Plovdiv, 2006

3. Petrova V., Krivoshapkova M. Kachamakov N., Man and Nature Class 3, Tilia, S., 2004

4. Skaf E. Heuristic learning mathematics: theory, methodology, technology, Donetsk: DonNU, 2004

5. R. Slavin, Pedagogical Psychology, Sofia: Science and Art Ltd., 2004

6. Dörner, D., Problemlösen als Informationsverarbeitung, 2.Auflage. Stuttgart, Kohlhammer, 1979. 